$R u_{6}$ Triangular Molecular Assembly

\section{Solid-State Supramolecular Organization of Supermolecules into a Truly Molecular Zeolite**}

\author{
Kom-Bei Shiu, * Hong-Chan Lee, Gene-Hsiang Lee, \\ Bao-Tsan Ko, Yu Wang, and Chu-Chieh Lin
}

Both inorganic zeolites and organic zeolitelike solids are attracting intense interest currently because of their functional properties. ${ }^{[1]}$ However, in contrast to many network porous materials with permanent porosity after partial or total removal of guests, ${ }^{[2]}$ zero-dimensional (i.e. discrete) analogues are scarce in the literature. ${ }^{[3]}$ The inherent difficulty in stabilizing such a material arises from the lack of structural rigidity, from its low thermal stability, and from the closepacking requirement of the molecular entities to minimize the Gibbs free energy by filling the voids in the structure. ${ }^{[4]}$ Herein, we present a truly molecular zeolite with both

[*] Prof. Dr. K.-B. Shiu, H.-C. Lee

Department of Chemistry

National Cheng Kung University

Tainan City 701 (Taiwan)

Fax: (+886) 6-274-0552

E-mail: kbshiu@mail.ncku.edu.tw

G.-H. Lee, Prof. Dr. Y. Wang

Instrument Center

National Taiwan University

Taipei 106 (Taiwan)

B.-T. Ko, Prof. Dr. C.-C. Lin

Instrument Center

National Chung-Hsing University

Taichung 402 (Taiwan)

[**: This work was supported by the National Science Council of the Republic of China for financial support of this research (Contract No. NSC89-2113-M006-019 and NSC90-2113-M006-021). We thank Prof. Dr. H. Teng of Chemical Engineering Department of National Cheng Kung University for measuring the BET area of the molecular zeolite.

().

Supporting information for this article is available on the WWWW under http://www.angewandte.org or from the author. structural rigidity and suitable thermal stability. The formation of this solid through cooperative self-assembly of unique triangular-tube organometallic supermolecules in both solution and the solid state is apparently driven positively by the close packing requirement in the molecular crystals. This material contains two types of 1D channels that are filled with solvent guests. However, the rigid nature of the solid architecture not only allows the complete removal of the molecular guests at ambient temperature without collapse of framework, but also has high thermal stability. Interestingly, the water molecules adsorbed into the microporous material also increase its thermal stability.

The treatment of $\left[\mathrm{Ru}_{3}(\mathrm{CO})_{12}\right]$ with 4,4'-biphenyldicarboxylic acid, followed by the addition of $\mathrm{PPh}_{3}$, produced eclipsed$\left[\left\{\mathrm{Ru}_{2}(\mathrm{CO})_{4}\left(\mathrm{PPh}_{3}\right)_{2}\right\}\left(\mu-4,4^{\prime}-\mathrm{O}_{2} \mathrm{CC}_{6} \mathrm{H}_{4} \mathrm{C}_{6} \mathrm{H}_{4} \mathrm{CO}_{2}\right)\right]_{3}$ (1) ${ }^{[5]}$ Complex 1 is air-stable when solid and readily soluble in acetone and $\mathrm{CH}_{2} \mathrm{Cl}_{2}$, indicative of molecular aggregates in the solid state. Indeed, as determined by single-crystal X-ray crystallography at $150 \mathrm{~K}$, the crystal structure of $\mathbf{1}$ consists of discrete molecules in a shape of an equilateral-triangle shaped tube (Figure 1). The single crystals, grown from $\mathrm{CH}_{2} \mathrm{Cl}_{2}$ /

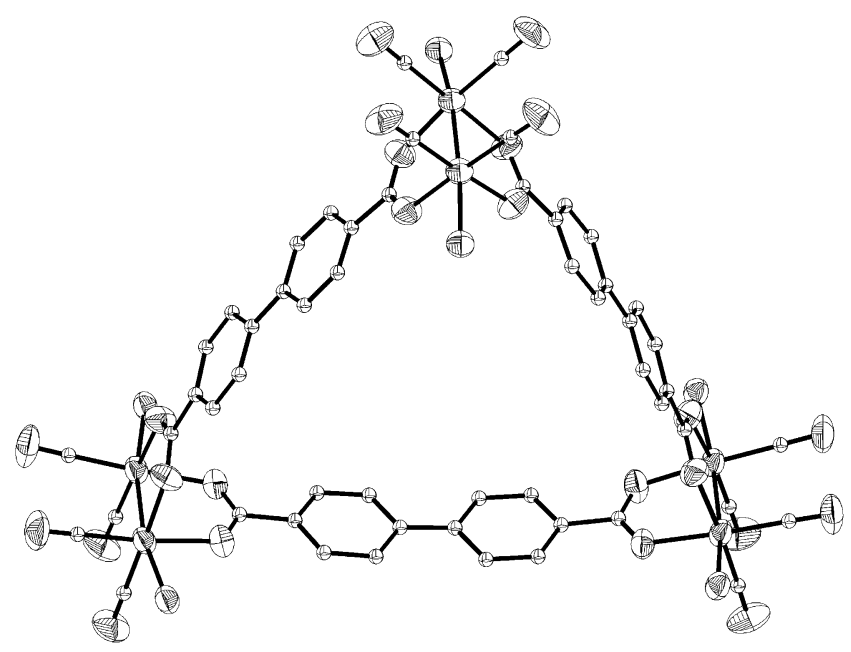

Figure 1. Triangular-tube supermolecule, 1 (ORTEP plot, thermal ellipsoids at the $50 \%$ probability level). All phenyl groups and hydrogen atoms are omitted for clarity.

$\mathrm{MeOH}$, were found to contain many solvent guests are present (Figure 2). The six bonded phosphane ligands, which are situated on the rims of two tube openings, do not close the tube but allow guests to move in and out. The triangle edge, which has a length of $15.340(1) \AA$, is defined by the midpoints of the $\mathrm{Ru}-\mathrm{Ru}$ bonds, whereas the depth of the tube is determined approximately by the $\mathrm{Ru}-\mathrm{Ru}$ bond length (about $2.7 \AA)$.

Molecules of 1 were packed in a hexagonal closest packing (hcp) arrangement with alternating ABAB layers. Except for the guest molecules, each lattice contains two molecular units: one unit in the A layer is symmetrically related by a screw $6_{3}$ axis to another in the B layer (Figure 2 and 3). A noncovalent association between the phenyl groups of the phosphane, attracted through edge-to-face $\pi-\pi$ stacking interactions ${ }^{[6]}$ can also be observed (Figure 3). Interestingly, apart from 


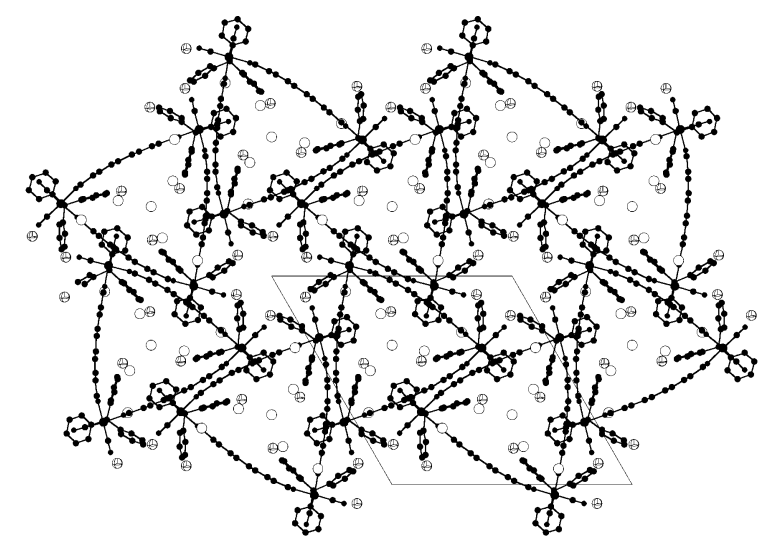

Figure 2. Packed structure of solvated 1 in the solid state along [001] with filled spheres for nonhydrogen atoms of molecule 1, hollow spheres for $\mathrm{CH}_{2} \mathrm{Cl}_{2}$, and octant-shaded spheres for $\mathrm{MeOH}$. The central hollow sphere inside the trigonal channel contains two disordered $\mathrm{CH}_{2} \mathrm{Cl}_{2}$ molecules at two different depths. All the hydrogen atoms of $\mathbf{1}$ have been omitted for clarity.

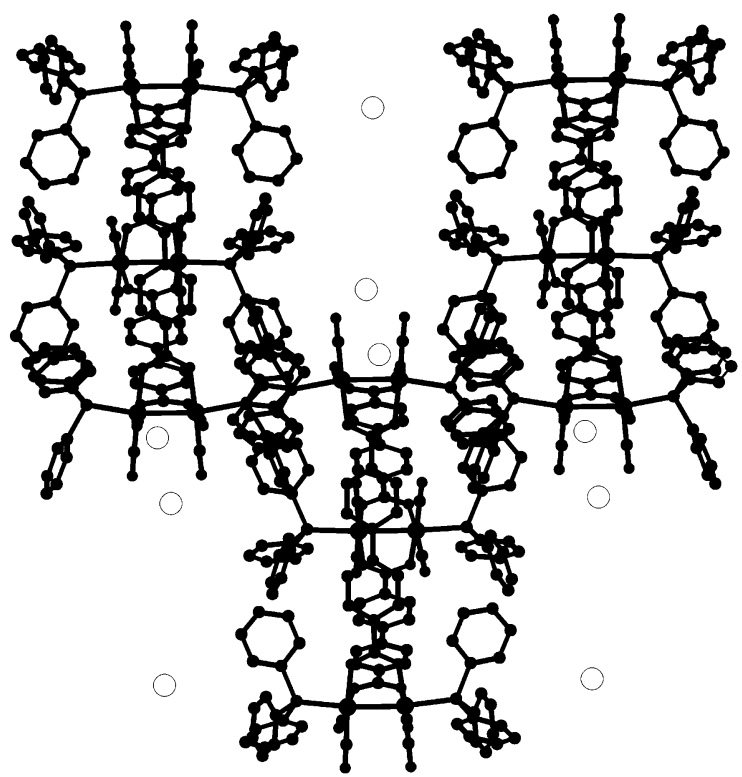

Figure 3. The clefts between two triangular-tube molecules with each cleft containing three $\mathrm{CH}_{2} \mathrm{Cl}_{2}$ molecules shown as hollow spheres.

the intrinsic 1D trigonal channels (Figure 1), the interstices in $\mathbf{1}$ also form another 1D "trigonal" channel, which has three $\mathrm{MeOH}$ located within, but viewed as a 1D "hexagonal" channel has six hexagonally distributed $\mathrm{MeOH}$ molecules in the projection plot (Figure 2). Each hexagonal opening has an edge length of about 13.12(1) A. Two separate locations within the trigonal channel were found to accept solvent guests: five $\mathrm{CH}_{2} \mathrm{Cl}_{2}$ and three $\mathrm{MeOH}$ molecules are located inside the triangular tube and three $\mathrm{CH}_{2} \mathrm{Cl}_{2}$ molecules (each at an average position of two disordered sites) are in the clefts between two triangular tubes and close to the three rims of the molecular triangle (Figure 2 and 3 ).

After one day, all solvated crystals remain transparent when viewed with an optical microscope. However, after the crystals were exposed to air at ambient temperature for several hours, the solvent guests evaporated, while the crystals absorbed moisture from the atmosphere. A thermal gravimetric analysis (TGA) of some of these crystals showed a $0.04 \%$ weight loss at $81.8^{\circ} \mathrm{C}$, which corresponds to the loss of $0.1 \mathrm{H}_{2} \mathrm{O}$ molecules per formula unit. Decomposition of the compound occurred at $203.8^{\circ} \mathrm{C}$ with another weight loss of $2.46 \%$, which corresponds to the loss of $2.5 \mathrm{CO}$ molecules per formula unit (Figure $4 \mathrm{a}$ ). The release of water at $81.8^{\circ} \mathrm{C}$ was
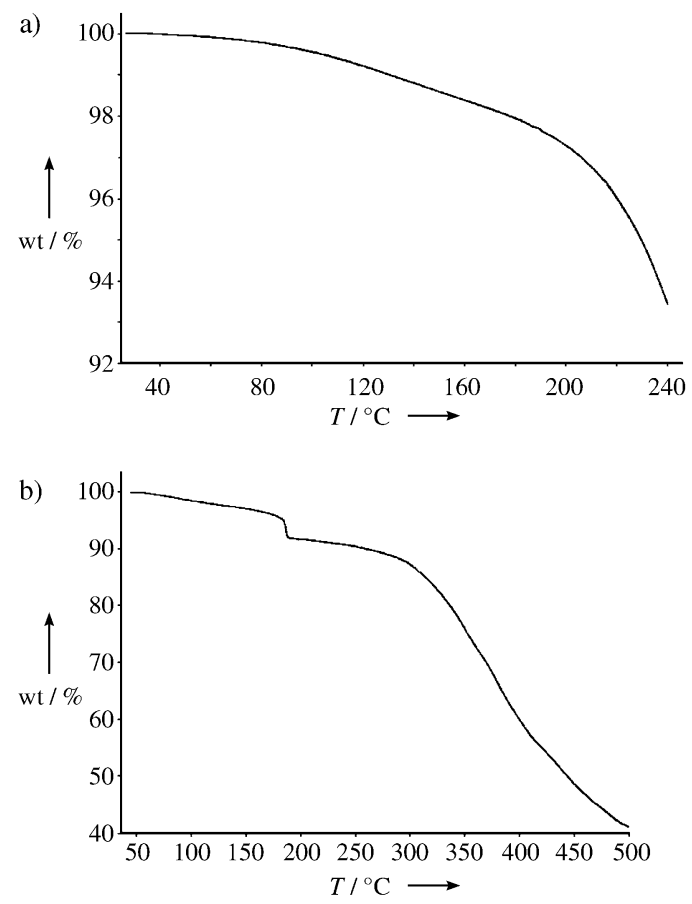

Figure 4. Thermal gravimetric analyses for a) solvated- and b) desolvated-crystals of 1 . Wt $=$ residual weight fraction.

also confirmed by a ${ }^{1} \mathrm{H}$ NMR study of the product. Interestingly, TGA of some desolvated crystals, obtained after carefully pumping off the solvents, showed that the thermal decomposition occurs at a lower temperature, $181.1^{\circ} \mathrm{C}$ (Figure $4 \mathrm{~b}$ ). Hence, it is evident that the adsorbed water molecules increase the thermal stability of the molecular framework in $\mathbf{1}$.

To understand the framework rigidity and the increased thermal stability of $\mathbf{1}$ during the drying process, the singlecrystal X-ray analysis of an air-dried crystal at $293 \mathrm{~K}$ was carried out. Both solvated and air-dried single crystals of $\mathbf{1}$ maintain an identical space group, $P 6_{3} / m$, but with slightly longer unit-cell lengths and a larger volume $(a=b=$ 23.8883(18), $c=20.202(2) \AA$, and $\left.V=9984.0(15) \AA^{3}\right)$ in the air-dried crystal relative to the solvated one $(a=b=$ 23.5248(5), $c=20.0767(5) \AA$, and $V=9622.2(4) \AA^{3}$ ), probably arising from thermal expansion, which is further supported by the similarity observed in most bond lengths, but not bond angles. Differential scanning calorimetry (DSC) of some typical air-dried crystals showed water desorption, but no apparent phase change up to $175^{\circ} \mathrm{C}$. The framework of $\mathbf{1}$ remains rigid through noncovalent interactions between 150 and $448 \mathrm{~K}$. 
From the Fourier difference maps of the air-dried structure 1 (Figure 5), the location of the water molecules in each lattice were assigned on the basis of three residual electron peaks (between 1.1 and 1.3 e $\AA^{-3}$ ). ${ }^{[5 a]}$ Coincidentally, the locations of six water molecules in the air-dried crystal are

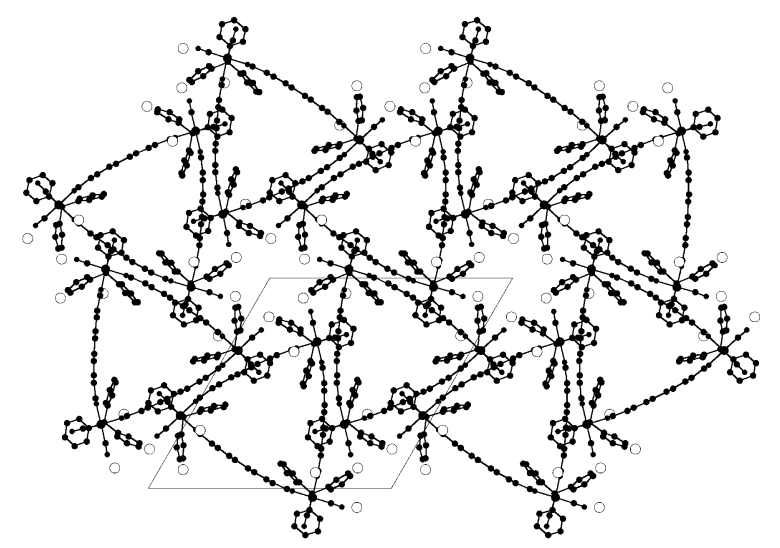

Figure 5. Packing structure of air-dried 1 in the solid state along [001]. All hydrogen atoms are omitted for clarity. Water molecules are shown as hollow spheres.

close to those of $\mathrm{MeOH}$ guests in the hexagonal channels of the solvated crystal, and the locations of six other water molecules are also close to those of $\mathrm{CH}_{2} \mathrm{Cl}_{2}$ guests inside the clefts (compare Figure 2 with Figure 5). It appears that the dipole-dipole attractive interactions between the polar surface of the porous adsorbent, $\mathbf{1}$, and the water adsorbates direct site-selective adsorption. However, it is still a physisorption rather than chemisorption, as the closest distances between any water oxygen atom and any other nearby atom, hydrogen or nonhydrogen, are all longer than 3.6 A. Apparently, the hydrophilic water molecules push the nearby hydrophobic phenyl groups of the phosphane ligands closer together through edge-to-face $\pi-\pi$ stacking interactions, ${ }^{[6]}$ thus increasing both the rigidity and thermal stability of the framework and raising the decomposition temperature from $181.1^{\circ} \mathrm{C}$ for the desolvated crystals, to $203.8^{\circ} \mathrm{C}$ for the airdried crystals. The hydrophilic $\mathrm{MeOH}$ molecules, used as one of two crystallization solvents for $\mathbf{1}$, may also exert similar hydrophobic-hydrophilic interactions, thus facilitating the preorganization of $\mathbf{1}$, through intermolecular noncovalent association of phenyl groups of the phosphane ligands, into the porous material. Based on the van der Waals volumes of $\mathrm{CH}_{2} \mathrm{Cl}_{2}$ and $\mathrm{MeOH},{ }^{[7]}$ we find that in the solvated $\mathbf{1}$, the guest molecules- $16 \mathrm{CH}_{2} \mathrm{Cl}_{2}$ and $12 \mathrm{MeOH}$-have a volume of $1.354 \AA^{3}$, which is $14 \%$ of the unit cell volume. A sorption experiment with an adsorbate, $\mathrm{N}_{2}$, and $\mathbf{1}$ as the adsorbent at 77.35 K was also carried out. An apparent BET surface area of $16.12 \mathrm{~m}^{2} \mathrm{~g}^{-1}$ with a corresponding pore volume of $0.049 \mathrm{~cm}^{3} \mathrm{~cm}^{-3}$ was obtained.

The results presented herein reveal that a truly molecular zeolite with suitable thermal stability and structural rigidity can be readily synthesized by using tetracarbonyl- and diphosphane-ligated diruthenium as building blocks and dicarboxylates as links. Future investigations will focus on the synthesis and characterization of similar porous materials with larger pores, elongated triangular tubes, and/or chiral channels by using suitable dicarboxylate links.

Received: February 10, 2003

Revised: April 28, 2003 [Z51149]

Keywords: microporous materials - noncovalent interactions · self-assembly · supramolecular chemistry · zeolite analogues

[1] I. W. C. E. Arends, R. A. Sheldon, M. Wallau, U. Schuchardt, Angew. Chem. 1997, 109, 1190; Angew. Chem. Int. Ed. Engl. 1997, 36,1144 , and references therein.

[2] a) H. Li, M. Eddaoudi, T. L. Groy, O. M. Yaghi, J. Am. Chem. Soc. 1998, 120, 8571; b) H. Li, M. Eddaoudi, M. O'Keeffe, O. M. Yaghi, Nature 1999, 402，276; c) S. S. Y. Chui， S. M. F. Lo, J. P. H. Charmant, A. G. Orpen, I. D. Williams, Science 1999, 283, 1148; d) C. J. Kepert, M. J. Rosseinsky, Chem. Commun. 1999, $375-$ 376; e) K. Biradha, Y. Hongo, M. Fujita, Angew. Chem. 2000, 112, 4001-4003; Angew. Chem. Int. Ed. 2000, 39, 3843-3845; f) M. Eddaoudi, H. Li, O. M. Yaghi, J. Am. Chem. Soc. 2000, 122, 1391; g) B. Chen, M. Eddaoudi, T. M. Reineke, J. W. Kampf, M. O'Keeffe, O. M. Yaghi, J. Am. Chem. Soc. 2000, 122, 1155911560 ; h) M. Kondon, M. Shimamura, S. Noro, S. Minakoshi, A. Asami, K. Seki, S. Kitagawa, Chem. Mater. 2000, 12, 1288; i) K. Seki, Chem. Commun. 2001, 1496; j) G. Papaefstathiou, L. R. MacGillivray, Angew. Chem. 2002, 114, 2174-2177; Angew. Chem. Int. Ed. 2002, 41, 2070-2073.

[3] G. A. Mines, B.-C. Tzeng, K. J. Stevenson, J. Li, J. T. Hupp, Angew. Chem. 2002, 114, 162-165; Angew. Chem. Int. Ed. 2002, 41, 154-157.

[4] a) A. I. Kitaigorodsky, Molecular Crystals and Molecules, Academic Press, New York, 1973; b) A. Gavezzotti, Acc. Chem. Res. 1994, 27, 309; c) M. U. Schmidt, U. Englert, J. Chem. Soc. Dalton Trans. 1996, 2077.

[5] a) See Supporting Information for details of synthesis and characterization, crystal data for solvated and air-dried structures of $\mathbf{1}$, and the assignment for the adsorbed water locations in airdried 1. b) CCDC-192219 (solvated 1) and 192221 (air-dried 1) contain the supplementary crystallographic data for this paper. These data can be obtained free of charge via www.ccdc.cam. ac.uk/conts/retrieving.html (or from the Cambridge Crystallographic Data Centre, 12 Union Road, Cambridge CB21EZ, UK; fax: (+44)1223-336-033; or deposit@ccdc.cam.ac.uk).

[6] J. W. Steed, J. L. Atwood, Supramolecular Chemistry, Wiley, New York, 2000, p. 26.

[7] Y. Marcus, The Properties of Solvents, Wiley, New York, 1998. 